Article

\title{
Boron and Nitrogen Co-Doped Porous Carbons Synthesized from Polybenzoxazines for High-Performance Supercapacitors
}

\author{
Lijun Bai ${ }^{1}$, Yanping Ge ${ }^{1}$ and Lizhong Bai ${ }^{2,3, *}$ \\ 1 Department of Fundamental Education, Shanxi Institute of Technology, Yangquan 045000, Shanxi, China; \\ bailijun@sxit.edu.cn (L.B.); geyanping@sxit.edu.cn (Y.G.) \\ 2 College of Optical Science and Engineering, Zhejiang University, Hangzhou 310058, China \\ 3 Shanxi Province Key Laboratory of Functional Nanocomposite Materials, North University of China, \\ Taiyuan 030051, China \\ * Correspondence: lzbai@nuc.edu.cn; Tel.: +86-571-879-53979 or +86-351-355-9669
}

Received: 28 August 2019; Accepted: 8 October 2019; Published: 11 October 2019

\begin{abstract}
Boron and nitrogen co-doped porous carbons (BNPC-X) were synthesized from boron-containing polybenzoxazines through carbonization and chemical activation, where $\mathrm{X}$ represents the weight ratio of boric acid to benzoxazine resin. The as-prepared BNPC-X were characterized by X-ray diffraction, scanning electron microscopy, X-ray photoelectron spectroscopy, element analysis and electrochemical measurements. The results show that the BNPC-0.15 possesses relatively high weight fractions of boron $(2.97 \mathrm{wt} \%)$ and nitrogen $(2.43 \mathrm{wt} \%)$, a homogeneous pore distribution, and remarkable electrochemical capacitive performance. It exhibits high specific capacitance $\left(286 \mathrm{~F} \cdot \mathrm{g}^{-1}\right.$ at $\left.0.05 \mathrm{~A} \cdot \mathrm{g}^{-1}\right)$, excellent rate capability (at A.g $\left.{ }^{-1}\right)$, and good charge-discharge stability ( $>92 \%$ capacitance retention after 1,000 cycles at $1.0 \mathrm{~A} \cdot \mathrm{g}^{-1}$ ) in $6 \mathrm{M} \mathrm{KOH}$ aqueous solution.
\end{abstract}

Keywords: boron and nitrogen co-doped; porous carbons; boron-containing polybenzoxazines; supercapacitors

\section{Introduction}

Supercapacitors have gained more and more attention in the field of energy storage for electronic devices, electric vehicles and industrial equipment because they possess a high specific power density, rapid charge-discharge rate and stable cycling life compared with lithium batteries [1-3]. Porous carbons, metal oxides, and conducting polymers are the most commonly used electrode materials for supercapacitors [4-7]. Among these materials, porous carbons with large specific surface areas and suitable pore structures are regarded as the most hopeful electrode materials owing to their stable physicochemical properties, extensive sources, good electrical conductivity, easy processability, and low cost [8-10]. Nevertheless, traditional porous carbon-based supercapacitors show a small energy density from 5 to $10 \mathrm{Wh} / \mathrm{kg}$, which seriously restricts their practical application in energy capture and storage [11-14]. Therefore, great efforts have been devoted to the synthesis of the high specific capacitance of new carbon materials to enhance their energy density [15-17].

Heteroatoms (such as boron, nitrogen, oxygen, phosphorus, and sulfur) doped into the carbon framework have been regarded as an effective strategy to enhance the specific capacitance of carbon materials [18]. These heteroatoms can supply a reversible pseudocapactiance from Faradaic electrochemical reactivity, increase electrical conductivity, and promote interface wettability [19]. More efforts have been dedicated to incorporating electron-deficient boron and electron-rich nitrogen into carbon materials for supercapacitors in recent years, which may tune their electronic structure and density of state due to the synergetic effect [20-25]. For example, Li et al. reported that boron 
and nitrogen co-doped graphene-like carbon (BNC) was synthesized by ball-milling and calcination two-step methods. The BNC-900 can display a high specific capacitance of $254 \mathrm{~F} \cdot \mathrm{g}^{-1}$ at $0.25 \mathrm{~A} \cdot \mathrm{g}^{-1}$ and reach a good capacitance retention of $78.2 \%$ at $100 \mathrm{~A} \cdot \mathrm{g}^{-1}$ [20]. Zhou et al. prepared boron and nitrogen co-doped porous carbon (BNC-OA) by the carbonization of the mixture of boric acid and oxidized asphaltene (OA) at $1173 \mathrm{~K}$ in an argon atmosphere, which shows the highest capacitance of $335 \mathrm{~F} \mathrm{~g}^{-1}$ at a current density of $0.1 \mathrm{~A} \cdot \mathrm{g}^{-1}$ and a capacitance retention of $83 \%$ at $1 \mathrm{~A} \mathrm{~g}^{-1}$ [21]. Yang et al. prepared boron and nitrogen-containing porous carbon nanofibers (BN-CNFs) through one-step electrospinning using boric acid $\left(\mathrm{H}_{3} \mathrm{BO}_{3}\right)$ and urea as boron and nitrogen precursors. The specific capacitance of the BN-CNFs was $180 \mathrm{~F} \cdot \mathrm{g}^{-1}$ at $1 \mathrm{~mA} \cdot \mathrm{cm}^{-2}$ [22]. You et al. reported a novel and facile method for the synthesis of $\mathrm{B}$ and $\mathrm{N}$ co-doped carbon networks by the pyrolysis of agarose hydrogel containing TBE buffer (Tris (tris (hydroxymethyl) aminomethane)/Boric acid/EDTA (ethylenediaminetetra acetic acid)) and chemical activation $(\mathrm{KOH})$, which exhibits a high specific capacitance of $214 \mathrm{~F} \cdot \mathrm{g}^{-1}$ at $0.2 \mathrm{~A} \cdot \mathrm{g}^{-1}$ in $6 \mathrm{M} \mathrm{KOH}$ electrolyte [23]. Jiang et al. synthesized nitrogen and boron co-doped activated porous carbons (BKACS) by carbonization, $\mathrm{KOH}$ chemical activation and a subsequent hydrothermal doping reaction using chitosan as a carbon source. BKACS can reach a high specific capacitance of $316 \mathrm{~F} \cdot \mathrm{g}^{-1}$ at $0.2 \mathrm{~A} \cdot \mathrm{g}^{-1}$ and exhibits a good capacitance retention of $94.08 \%$ after 10,000 cycles at $10 \mathrm{~A} \cdot \mathrm{g}^{-1}$ in the $6 \mathrm{M} \mathrm{KOH}$ electrolyte [24]. Dai et al. synthesized vertically aligned boron carbon nitride nanotubes (VA-BCNs) from a melamine diborate precursor. The resultant VA-BCNs grown at $1000{ }^{\circ} \mathrm{C}$ show the highest specific capacitance (321.0 F.g $\mathrm{g}^{-1}$ at $0.2 \mathrm{~A} \cdot \mathrm{g}^{-1}$ ) due to synergetic effects [25]. Therefore, developing novel $\mathrm{B}$ and $\mathrm{N}$ co-doped carbon materials with a high specific capacitance, good rate performance, and excellent cycle stability for supercapacitors remains a challenge [26].

In this paper, we synthesized boron and nitrogen co-doped nanoporous carbons (BNPC-X) derived from the boron-containing polybenzoxazines by carbonization and $\mathrm{KOH}$ chemical activation. The boron-containing polybenzoxazines were prepared from benzoxazine resin and boric acid. In the BNPC-X, benzoxazine resin functions as a carbon and nitrogen precursor, while boric acid acts as the boron source. The BNPC-X are found to possess an enhanced electrochemical performance in supercapacitors compared with the NPC in the absence of boron acid in terms of specific capacitance, rate capability, and cycling stability.

\section{Experimental}

\subsection{Synthesis}

Benzoxazine resin was purchased from Kerrben Polymer New Material Co. Ltd. (Zibo, China) All of the other chemicals were used without further purification. Nanoporous carbons with different boron and nitrogen contents were prepared from boron-containing polybenzoxazines by adjusting the weight ratio of boric acid to benzoxazine resin (5:100, 10:100, 15:100). In a typical process, $10.0 \mathrm{~g}$ of benzoxazine resin and $0.5 \mathrm{~g}$ of boric acid were dissolved in $40 \mathrm{~mL}$ DMF. Then, the solution was heated at $80^{\circ} \mathrm{C}$ for $6 \mathrm{~h}$ to vaporize the DMF, and then cured at $200^{\circ} \mathrm{C}$ for $2 \mathrm{~h}$. The obtained polybenzoxazine was further carbonized at $500^{\circ} \mathrm{C}$ for $2 \mathrm{~h}$ with a heating rate of $5^{\circ} \mathrm{C} \cdot \mathrm{min}^{-1}$ in the nitrogen flow. Subsequently, the obtained carbonized material was mixed with $\mathrm{KOH}$ at a mass ratio of $1: 1$, and the mixture was heated in a tube furnace at $70{ }^{\circ} \mathrm{C}$ for $1 \mathrm{~h}$ with a heating rate of $5{ }^{\circ} \mathrm{C} \cdot \mathrm{min}^{-1}$ under a nitrogen atmosphere. Finally, the obtained sample was repeatedly washed with dilute $\mathrm{HCl}$ solution and deionized water until the $\mathrm{pH}$ reached 7 and dried at $120^{\circ} \mathrm{C}$ for $12 \mathrm{~h}$. The as-prepared nanoporous carbons were denoted as BNPC- $X$ (where $X$ represents the weight ratio of boric acid to benzoxazine resin). For comparison, the nanoporous carbon (NPC) was synthesized by the above strategy in the absence of boric acid.

\subsection{Characterization}

Powder X-ray diffraction (XRD) patterns were determined with a D8 Advance diffractometer (Bruker, Germany) with using mono-chromated $\mathrm{Cu} \mathrm{K} \alpha$ radiation $(\lambda=0.15406 \mathrm{~nm})$. Scanning electron microscopy (SEM) and energy dispersive $X$-ray spectrometry (EDS) investigations were 
carried out with a S-4800 microscope (JEOL, Tokyo, Japan) and GENENIS-4000 instrument (EDAx, Berwyn, Pennsylvania, USA), respectively. X-ray photoelectron spectroscopy (XPS) were obtained on an AXIS Ultra DLD spectrometer (Kratos, Manchester, UK) with an Mg K $\alpha$ exciting source (1253.6 eV). The spectra were referenced to $C 1$ s peak at $284.5 \mathrm{eV}$. Elemental analysis was further performed by an Vario Macro Cube micro-analyzer (Elementar, langenselbold, Germany). The element content was calculated by different detection modes.

\subsection{Electrochemical Measurements}

For this measurement, $80 \mathrm{wt} \%$ electroactive materials, $10 \mathrm{wt} \%$ carbon black and $10 \mathrm{wt} \%$ polytetrafluoroethylene were uniformly mixed and then pressed on nickel foam $(1 \mathrm{~cm} \times 1 \mathrm{~cm})$. The mass loading of electroactive materials on the nickel foam was about $4 \mathrm{mg} \cdot \mathrm{cm}^{-2}$. The electrochemical performances of the as-prepared electrode were tested in a three-electrode system with $6 \mathrm{M}$ $\mathrm{KOH}$ aqueous electrolyte at room temperature. Cyclic voltammetry $(\mathrm{CV})$ and the galvanostatic charging-discharging test (GCD) were performed within the same voltage window-between -1.0 and $0 \mathrm{~V}$ (vs.SCE). Electrochemical impedance spectra (EIS) were conducted on an open circuit potential in the frequency range from $1 \mathrm{mHz}$ to $100 \mathrm{kHz}$ with a $5 \mathrm{mV}$ alternating current amplitude.

\section{Results and Discussion}

\section{Structure and Morphology Characterization}

The crystalline structure of the NPC and BNPC- $X$ were determined by XRD, and the results are displayed in Figure 1. It is found that all the samples exhibit two broad and low-intensive diffraction peaks centered at $2 \theta=20^{\circ}-26^{\circ}$ and $43^{\circ}-44^{\circ}$, which can be attributed to the (002) and (100) diffractions of the hexagonal graphitic carbon lattice, clearly indicating an amorphous nature and low graphitization degree of the nanoporous carbon materials [27,28]. The BNPC-X exhibit a gradual left shift of (002) and (100) peaks with the increase of the boron acid mass ratio, indicating a slight damage of the micro-graphitic structure of carbon materials $[29,30]$. Moreover, the intensity of the diffraction peak of BNPC-0.15 at a low angle is significant, showing the existence of abundant pores.

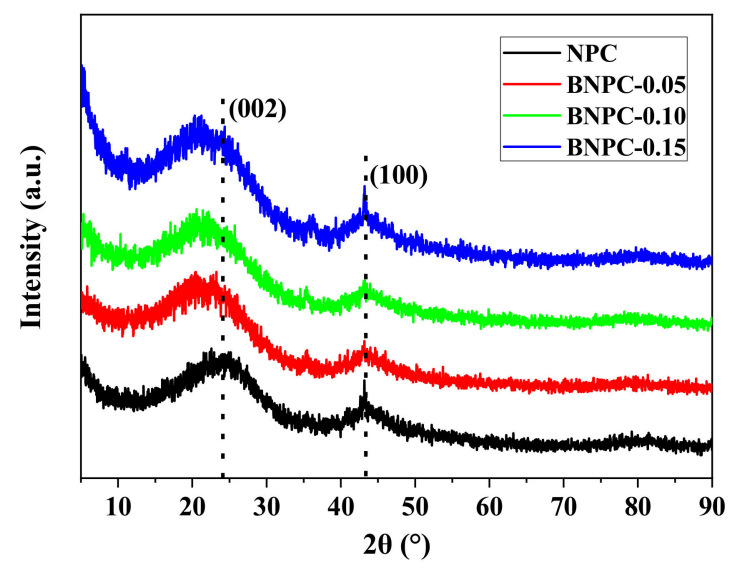

Figure 1. X-ray diffraction (XRD) patterns of the nanoporous carbon (NPC) and boron and nitrogen co-doped nanoporous carbons (BNPC-X).

The morphology and microstructure of the NPC and BNPC-X were characterized by scanning electron microscopy (SEM) and energy dispersive X-ray spectrometry (EDS), as shown in Figure 2. It can be seen that the NPC exhibits a rough surface with a few cavities or macropores in $0.2 \mu \mathrm{m}$ pore sizes, which results from the violent etching between carbon and $\mathrm{KOH}$ at high temperature (Figure 2a). However, the pore sizes of the BNPCs evidently became smaller, and more microporous channels can be developed and even interconnected with each other as the mass ratio increases from 
0.05 to 0.15 (Figure $2 \mathrm{~b}-\mathrm{d}$ ). It is reasonable that boron atoms are considered to be beneficial for $\mathrm{KOH}$ chemical activation for developing the micropores [31]. BNPC-0.15 possesses abundant mesopores and significant micropores with a diameter of appropriately $10 \mathrm{~nm}$, which are helpful for the fast transportation of electrolyte ions into the inner nanoporous carbon by minimizing the ion diffusion distance (Figure 2e) [32]. Besides this, the nature of doping in BNPC-0.15 can be clarified by the element mapping measurements according to the SEM image (Figure $2 \mathrm{f}-\mathrm{h}$ ), which clearly indicates the presence of $\mathrm{C}, \mathrm{B}$, and $\mathrm{N}$.
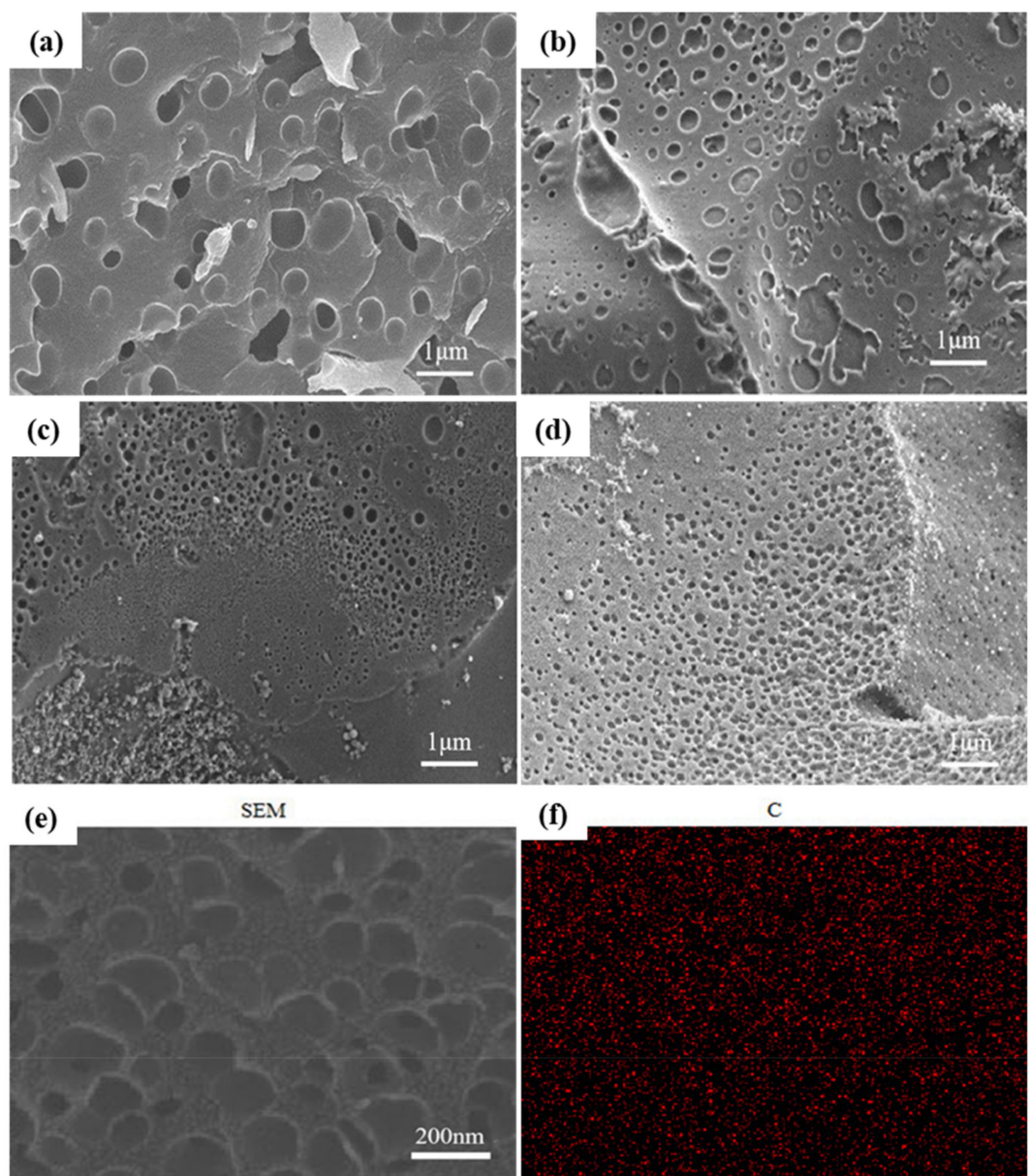

(f)

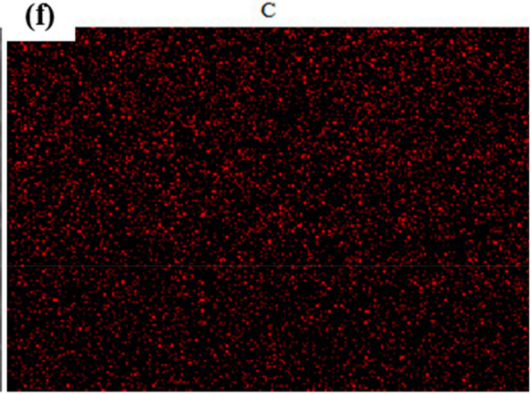

(g)

(h)
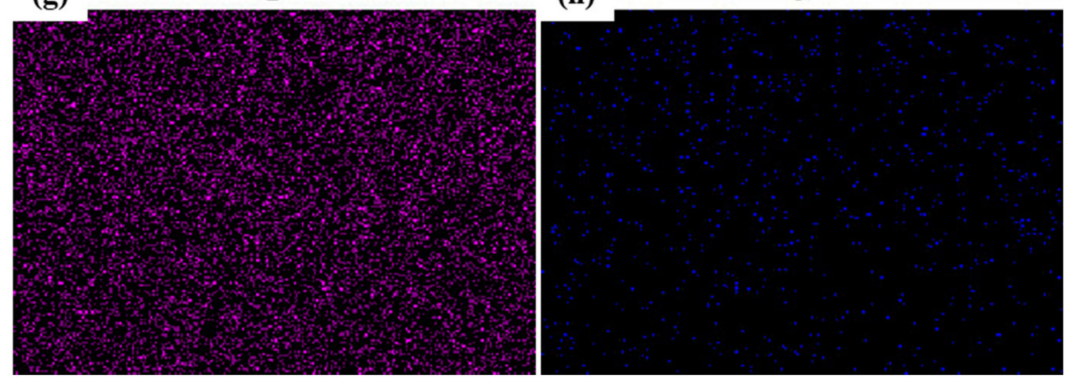

Figure 2. SEM images of the NPC (a), BNPC-0.05 (b), BNPC-0.10 (c) and BNPC-0.15 (d and e), and the elemental distribution of BNPC-0.15 probed by energy-dispersive spectroscopy (EDS) mapping (f-h).

The surface electronic state and composition of the NPC and BNPC-X were analyzed by X-ray photoelectron spectroscopy (XPS) and elemental analysis. Figure 3 exhibits the wide-scan XPS spectrum of all the samples and the fitted N1s and B1s XPS spectra of BNPC-0.15. As shown in Figure 3a, the NPC contains C, N, and O elements. Moreover, the BNPCs contain C, N, B and O atoms, indicating 
that boron can be successfully introduced into the carbon framework. As the initial weight ratio of boron acid to benzoxazine resin increased from 0.05 to 0.15 , the nitrogen content of BNPC-X decreased, and the boron element content increased gradually (Table 1). Three different types of nitrogen species can be distinguished on the $\mathrm{N}$ 1s spectrum: pyridinic nitrogen (N-6 at $398.5 \mathrm{eV})$, pyrrolic or pyridonic nitrogen ( $\mathrm{N}-5$ at $400.3 \mathrm{eV})$, and quaternary nitrogen ( $\mathrm{N}-\mathrm{Q}$ at $401.4 \mathrm{eV})$, respectively [28]. However, it can be found that the peak at $396.6 \mathrm{eV}$ could be assigned to the B 1s signal related to N-B bonding, which is characteristic for boron nitride. The B 1s XPS spectrum is deconvoluted into three peaks (Figure 3c). The peaks located at 398.5, 399.6, and $401.2 \mathrm{eV}$ can be assigned to B-N, B-C, and B-O species, respectively, demonstrating that the boron atoms are incorporated into the carbon network [33]. The nitrogen and boron-containing groups cannot only enhance the specific capacitance but can also improve the surface wettability at the electrode/electrolyte interface. The element composition of the NPC and BNPC-X is seen in Table 1. The element percentage of boron in NPC, BNPC-0.05, BNPC-0.10, and BNPC- 0.15 is calculated from the XPS survey spectra to be about $0,1.02,1.88$ and $2.75 \mathrm{wt} \%$, respectively, which is consistent with the elemental analysis results. Thereby, the XPS results prove that the boron and nitrogen atoms were successfully incorporated in the carbon lattice, which can generate primary pseudo-capacitance in an alkaline aqueous electrolyte.
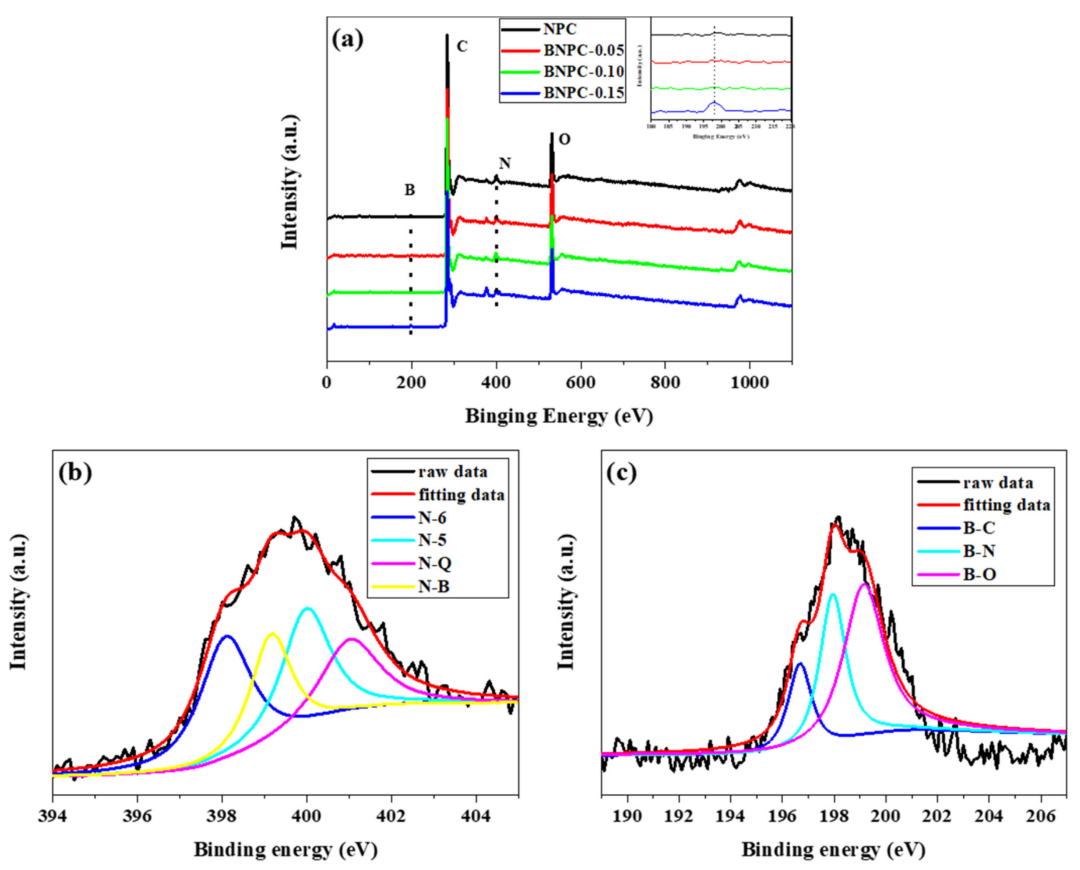

Figure 3. X-ray photoelectron spectroscopy (XPS) survey spectra of the NPC and BNPC-X (a), N 1s XPS spectrum (b) and B 1s XPS spectrum(c) of BNPC-0.15.

Table 1. Textural properties and elemental content of the NPC and BNPC-X.

\begin{tabular}{ccccc}
\hline \multirow{2}{*}{ Name } & \multicolumn{2}{c}{ XPS (wt \%) } & \multicolumn{2}{c}{ EA (wt \%) } \\
& $\mathbf{N}$ & $\mathbf{B}$ & $\mathbf{N}$ & $\mathbf{B}$ \\
\hline NPC & 3.25 & 0 & 3.42 & 0 \\
BNPC-0.05 & 2.84 & 1.02 & 3.07 & 1.15 \\
BNPC-0.10 & 2.73 & 1.88 & 2.95 & 2.03 \\
BNPC-0.15 & 2.25 & 2.75 & 2.43 & 2.97 \\
\hline
\end{tabular}

Cyclic voltammetry (CV) was used to probe the electrochemical capacitive behavior of the NPC and BNPC-X electrodes in a potential window from -1.0 to $0 \mathrm{~V} \cdot \mathrm{vs} \cdot \mathrm{SCE}$ in the $6 \mathrm{M} \cdot \mathrm{KOH}$ electrolyte. Figure 4 shows the CV curves of the NPC and BNPC-X electrodes at different scanning rates from 1 to $20 \mathrm{mV} \cdot \mathrm{s}^{-1}$. As shown in Figure $4 \mathrm{a}$, the CV curve of the NPC electrode shows a small deviation 
from the rectangular shape, with no obvious redox peaks. It can be discerned that the BNPC-X electrodes exhibit an ambiguous rectangular shape with a pair of obvious peaks, which may be caused by some pseudocapacitive effects with the increased the mass ratio of boron acid (Figure $4 b-d$ ). As the scanning rate increases, the rectangular shape becomes more distorted and the enclosed area decreases. This is due to the internal resistance of the current collector, electrode, and electrolyte, or the diffusion resistance at the electrode/electrolyte interface [34]. In particular, it can be noted that BNPC-0.15 can reach the largest specific capacitance among all the electrodes, and this may be attributed to the electrical double layer capacitance due to its own porous structure and additional pseudocapacitance resulting from the boron doping in the carbon electrodes (Figure 4d).
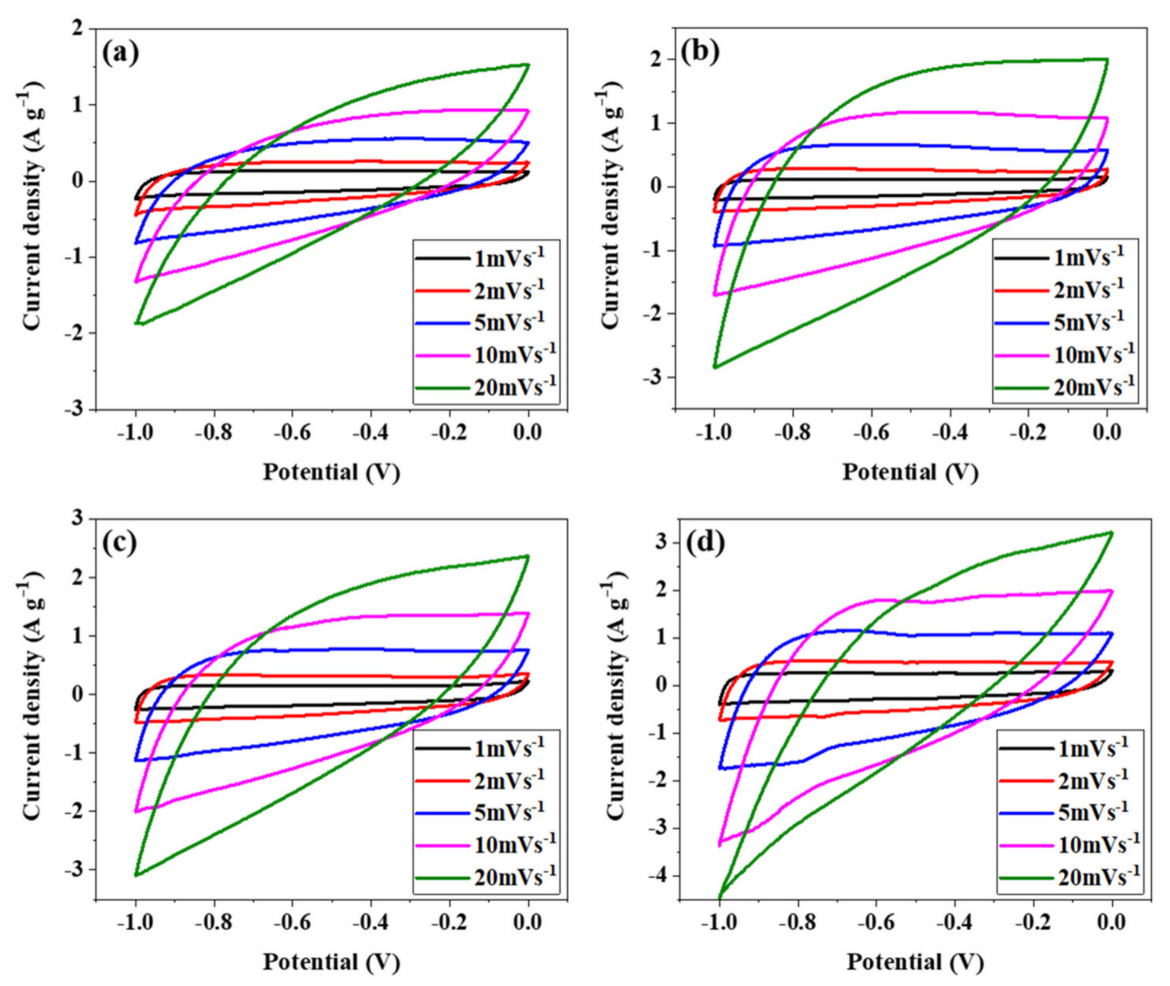

Figure 4. Cyclic voltammetry curves of the NPC (a), BNPC-0.05 (b), BNPC-0.10 (c) and BNPC-0.15 (d) at different scan rates.

The galvanostatic charging-discharging (GCD) test is the most practical tool to research the electrochemical behaviors of supercapacitors. Figure 5a exhibits the GCD curves of the NPC and BNPC-X electrodes at a current density of $0.05 \mathrm{~A} \cdot \mathrm{g}^{-1}$. The charge curves are nearly symmetrical to the corresponding discharge ones, suggesting that all the electrodes have typical electrical double layer capacitive behavior and good electrochemical reversibility. Moreover, the BNPC- 0.15 electrode exhibits the largest discharge time, indicating the largest specific capacitance, which is consistent with the CV results. The charge-discharge curves of the BNPC-0.15 electrode at different current densities from 0.05 to $1 \mathrm{~A} \mathrm{~g}^{-1}$ are shown in Figure $5 \mathrm{~b}$. All the curves exhibit a nearly symmetric triangular shape with slight curvature. The deviation from linearity for all charge-discharge curves is characteristic of a typical pseudo-capacitive behavior, which may be attributed to the boron-enriched groups by the carbonization of benzoxazine resin and boric acid. Besides this, the specific capacitance of the BNPC-0.15 electrode decreases gradually with the increasing discharge current density, suggesting that the electrolyte ion cannot transfer well into the inner structure of active materials due to the limited ion diffusion at a large current density. The specific capacitance $\left(C_{g}\right)$ was calculated according to $C_{g}$ $\left(\mathrm{F} \cdot \mathrm{g}^{-1}\right)=I \times \Delta t / \Delta E$, where $I$ is the discharge current density $\left(\mathrm{A} \cdot \mathrm{g}^{-1}\right), \Delta t$ is the discharge time (s), and $\Delta \mathrm{E}$ is the potential window after the IR drop. Figure $5 \mathrm{c}$ exhibits the specific capacitance at different current densities. The specific capacitances of all the electrodes decrease gradually with the increase 
of current density from 0.05 to $1 \mathrm{~A} \cdot \mathrm{g}^{-1}$. The BNPC- 0.15 can reach a highest specific capacitance of $286 \mathrm{~F} \cdot \mathrm{g}^{-1}$ at $0.05 \mathrm{~A} \cdot \mathrm{g}^{-1}$, higher than the capacitance of NPC $\left(167 \mathrm{~F} \cdot \mathrm{g}^{-1}\right), \mathrm{BNPC}-0.05\left(178 \mathrm{~F} \cdot \mathrm{g}^{-1}\right)$ and BNPC-0.10 (196 F.g $\left.{ }^{-1}\right)$, indicating that the boron doping may enhance the specific capacitance by pseudo-capacitance reaction. The enhancement of specific capacitance might be ascribed that the role of boron doping changes the surface performance to form more active centers, which could attract more anions from the electrolyte compared to carbon atoms [35]. Because long cycling stability is crucial for supercapacitor applications, the BNPC- 0.15 electrode was tested by using GCD cycles at a current density of $1 \mathrm{~A} \cdot \mathrm{g}^{-1}$. As shown in Figure $5 \mathrm{~d}$, the specific capacitance is $173 \mathrm{~F} \cdot \mathrm{g}^{-1}$ in the first cycle and still remains at $160 \mathrm{~F} \cdot \mathrm{g}^{-1}$ after 1000 cycles. Additionally, the capacitance retention stays at $92 \%$, suggesting excellent cycle stability. However, BNPC-0.05 generally has worse performance than the NPC in Figure $5 c, d$, which is attributed to the redox reaction not having enough time to occur on the surface of the electrode/electrolyte at high current densities [22].
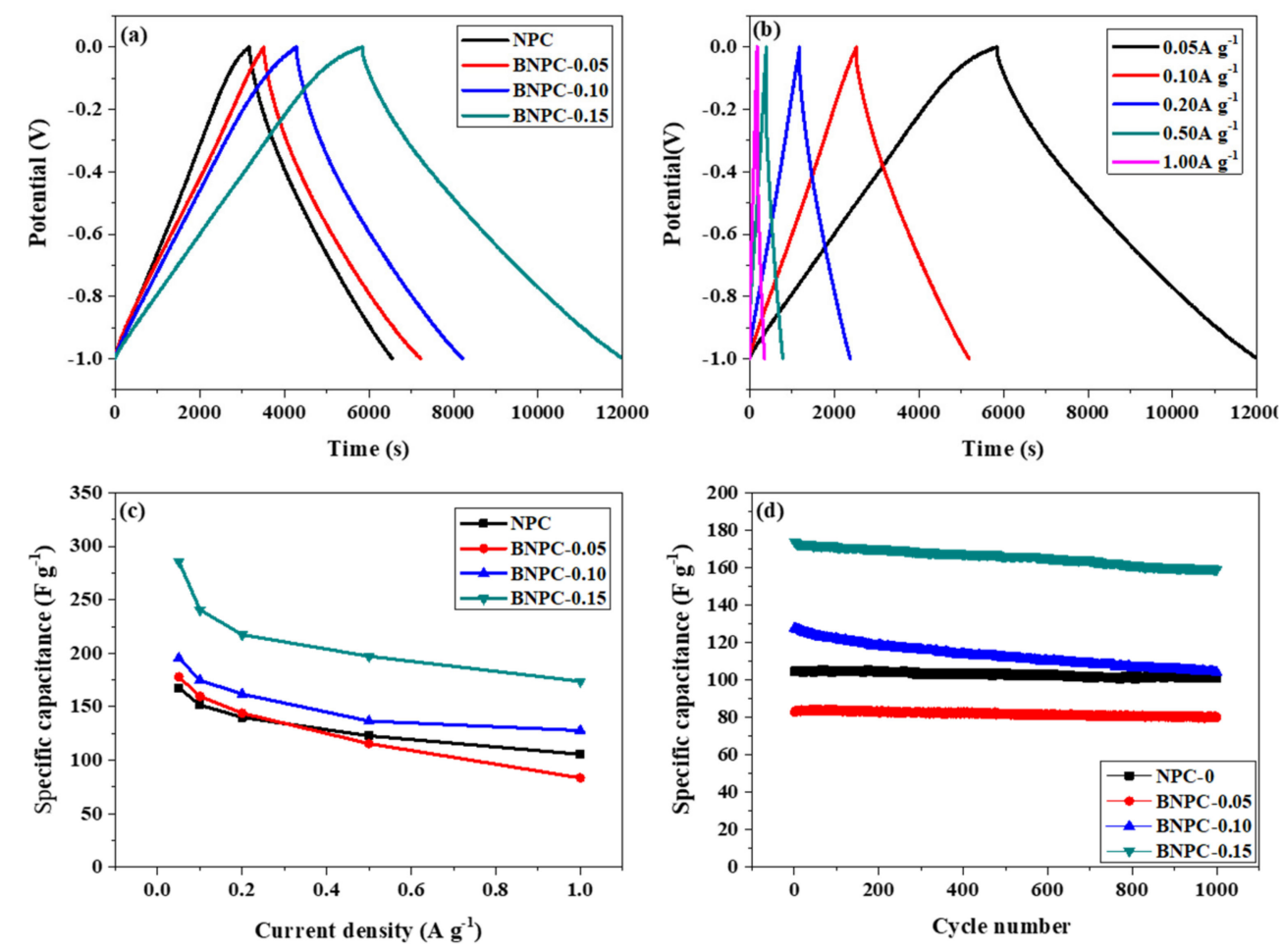

Figure 5. Galvanostatic charge-discharge (GCD) curves of the NPC and BNPC-X at a current density of $0.05 \mathrm{~A} \cdot \mathrm{g}^{-1}(\mathbf{a})$, GCD curves of the BNPC-0.15 at different current densities (b), the specific capacitances of the NPC and BNPC-X at different current densities (c), and the cycling stability of the NPC and BNPC-X at a current density of $1 \mathrm{~A} \cdot \mathrm{g}^{-1}(\mathbf{d})$.

Electrochemical impedance spectra (EIS) are further used to analyze the electrochemical performance of the electrode materials for supercapacitors. Figure 6 exhibits the AC impedance spectroscopy (Nyquist plots) of all the NPC and BNPC-X electrodes with an open circuit. Obviously, all the curves present a similar shape, which contain a semicircle at high frequency, a nearly $45^{\circ}$ sloped line at medium frequency and a nearly vertical line at low frequency. The straight line in the low-frequency area presents the specific capacitance of the carbon electrode [36]. It can be found that the BNPC-0.15 electrode exhibits the shortest line length in the low-frequency area, suggesting the highest specific capacitance. The semicircle presents the interfacial charge transfer resistance of the carbon electrode in the high-frequency region [37]. The smaller the diameter, the lower the interfacial charge transfer resistance. The BNPC- 0.15 electrode exhibits low charge transfer resistance and Warburg impedance in the high-frequency area, implying the fastest ion migration. This is not only due to the suitable pore 
structure of the carbon materials promoting the ion diffusion and transport, but is also because of the enhanced surface wettability after boron and nitrogen doping.

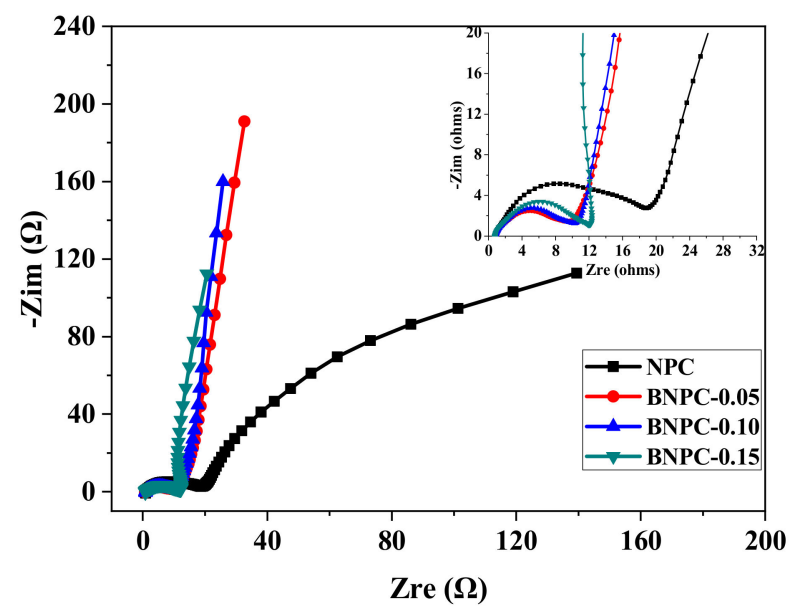

Figure 6. The Nyquist plots of the NPC and BNPC-X electrodes (the inset shows the expanded high-frequency region of the plots).

\section{Conclusions}

In summary, boron and nitrogen co-doped nanoporous carbons were prepared from boron-containing polybenzoxazines by $\mathrm{KOH}$ chemical activation, in which benzoxazine resin functioned as a carbon and nitrogen precursor while boric acid acted as the boron source. Boron and nitrogen-containing functionalities can not only make the BNPC-X electrodes interact with the electrolyte easily but also enhance the specific capacitance of the BNPC-X electrodes through redox reaction. As the initial weight ratio of boron acid to benzoxazine resin increased from 0.05 to 0.15 , the nitrogen content of BNPC-X decreased, and the boron content increased gradually. BNPC-0.15 possessed relatively high mass fractions of boron $(2.97 \mathrm{wt} \%)$ and nitrogen $(2.43 \mathrm{wt} \%)$ with uniform distribution. Besides this, BNPC- 0.15 possessed a very good capacitive performance of $286 \mathrm{~F} \cdot \mathrm{g}^{-1}$ at $0.05 \mathrm{~A} \cdot \mathrm{g}^{-1}$ and an excellent rate capability $\left(174 \mathrm{~F} \cdot \mathrm{g}^{-1}\right.$ at $\left.1 \mathrm{~A} \cdot \mathrm{g}^{-1}\right)$ and reached $92 \%$ capacitance retention after 1000 cycles. This makes it a promising alternative as a high-performance electrode material in supercapacitors.

Author Contributions: Conceptualization, L.B. (Lizhong Bai); Formal analysis, L.B. (Lijun Bai), Y.G., and L.B. (Lizhong Bai); Investigation, L.B. (Lijun Bai) and Y.G.; Methodology, L.B. (Lijun Bai) and L.B. (Lizhong Bai); Supervision, L.B. (Lizhong Bai); Writing-original draft, L.B. (Lijun Bai); Writing-review \& editing, L.B. (Lizhong Bai).

Funding: This research was funded by the Natural Science Foundation for Post-doctoral Scientists of China (No. 2019M652077) and the Natural Science Foundation of Shanxi Province (No. 201701D221088).

Acknowledgments: The authors acknowledge the support of Zhejiang University.

Conflicts of Interest: The authors declare no conflict of interest.

\section{References}

1. Li, X.; Wei, B.Q. Supercapacitors based on nanostructured carbon. Nano Energy 2013, 2, 159-173. [CrossRef]

2. Huang, P.; Lethien, C.; Pinaud, S.; Brousse, K.; Laloo, R.; Turq, V.; Respaud, M.; Demortière, A.; Daffos, B.; Taberna, P.L.; et al. On-chip and freestanding elastic carbon films for micro-supercapacitors. Science 2016, 351, 691-695. [CrossRef] [PubMed]

3. Kim, H.S.; Cook, J.B.; Lin, H.; Ko, J.S.; Tolbert, S.H.; Ozolins, V.; Dunn, B. Oxygen vacancies enhance pseudocapacitive charge storage properties of $\mathrm{MoO}_{3-\mathrm{x}}$. Nat. Mater. 2017, 16, 454-460. [CrossRef] [PubMed]

4. Wang, Y.G.; Xia, Y.Y. Recent progress in supercapacitors: From materials design to system construction. Adv. Mater. 2013, 25, 5336-5342. [CrossRef] [PubMed] 
5. Dong, Y.; Zhang, S.; Du, X.; Hong, S.; Zhao, S.N.; Chen, Y.X.; Chen, X.H.; Song, H.H. Boosting the electrical double-layer capacitance of graphene by self-doped defects through ball-milling. Adv. Funct. Mater. 2019, 29, 1901127. [CrossRef]

6. Feng, N.; Meng, R.J.; Zu, L.H.; Feng, Y.T.; Peng, C.X.; Huang, J.M.; Liu, G.L.; Chen, B.J.; Yang, J.H. A polymer-direct-intercalation strategy for $\mathrm{MoS}_{2} /$ carbon-derived heteroaerogels with ultrahigh pseudocapacitance. Nat. Commun. 2019, 10, 1372. [CrossRef] [PubMed]

7. Heydari Gharahcheshmeh, M.; Gleason, K.K. Device fabrication based on oxidative chemical vapor deposition (ocvd) synthesis of conducting polymers and related conjugated organic materials. Adv. Mater. Interfaces 2019, 6, 1801564. [CrossRef]

8. Dutta, S.; Bhaumik, A.; Wu, K.C.W. Hierarchically porous carbon derived from polymers and biomass: Effect of interconnected pores on energy applications. Energy Environ. Sci. 2014, 7, 3574-3592. [CrossRef]

9. Heo, Y.J.; Lee, J.W.; Son, Y.R.; Lee, J.H.; Yeo, C.S.; Lam, T.D.; Park, S.Y.; Park, S.J.; Sinh, L.H.; Shin, M.K. Large-Scale conductive yarns based on twistable korean traditional paper (Hanji) for supercapacitor applications: Toward high-performance paper supercapacitors. Adv. Energy Mater. 2018, 8, 1801854. [CrossRef]

10. Deng, T.; Zhang, W.; Arcelus, O.; Wang, D.; Shi, X.Y.; Zhang, X.Y.; Carrasco, J.; Rojo, T.; Zheng, W.T. Vertically co-oriented two dimensional metal-organic frameworks for packaging enhanced supercapacitive performance. Commun. Chem. 2018, 1, 6. [CrossRef]

11. Cui, J.F.; Xi, Y.L.; Chen, S.; Li, D.H.; She, X.L.; Sun, J.; Han, W.; Yang, D.J.; Guo, S.J. Prolifera-green-tide as sustainable source for carbonaceous aerogels with hierarchical pore to achieve multiple energy storage. Adv. Funct. Mater. 2016, 26, 8487-8495. [CrossRef]

12. Wei, J.S.; Ding, C.; Zhang, P.; Ding, H.; Niu, X.Q.; Ma, Y.Y.; Li, C.; Wang, Y.G.; Xiong, H.M. robust negative electrode materials derived from carbon dots and porous hydrogels for high-performance hybrid supercapacitors. Adv. Mater. 2019, 31, 1806197. [CrossRef] [PubMed]

13. Peng, H.R.; Yao, B.; Wei, X.J.; Liu, T.Y.; Kou, T.Y.; Xiao, P.; Zhang, Y.H.; Li, Y. Pore and heteroatom engineered carbon foams for supercapacitors. Adv. Energy Mater. 2019, 9, 1803665. [CrossRef]

14. Liu, Z.; Xiao, K.K.; Guo, H.; Ning, X.H.; Hu, A.P.; Tang, Q.L.; Fan, B.B.; Zhu, Y.F.; Chen, X.H. Nitrogen-doped worm-like graphitized hierarchical porous carbon designed for enhancing area-normalized capacitance of electrical double layer supercapacitors. Carbon 2017, 117, 163-173. [CrossRef]

15. Jiang, H.; Lee, P.S.; Li, C.Z. 3D carbon based nanostructures for advanced supercapacitors. Energy Environ. Sci. 2013, 6, 41-53. [CrossRef]

16. Kim, C.; Kang, D.Y.; Moon, J.H. Full lithographic fabrication of boron-doped 3D porous carbon patterns for high volumetric energy density microsupercapacitors. Nano. Energy 2018, 53, 182-188. [CrossRef]

17. Guo, W.; Zhou, Y.S.; Pang, L.; Chen, Z.; Dong, Y.H.; Bi, J.J.; Ming, S.J.; Li, T. One-step pyrolysis to synthesize non-graphitic nitrogen-doped $2 \mathrm{~d}$ ultrathin carbon nanosheets and their application in supercapacitors. ChemElectroChem 2019, 6, 2689-2697. [CrossRef]

18. Yang, W.; Yang, W.; Kong, L.N.; Song, A.L.; Qin, X.J.; Shao, G.J. Phosphorus-doped 3D hierarchical porous carbon for high-performance supercapacitors: A balanced strategy for pore structure and chemical composition. Carbon 2018, 127, 557-567. [CrossRef]

19. Wang, X.W.; Sun, G.Z.; Routh, P.; Kim, D.H.; Huang, W.; Chen, P. Heteroatom-doped graphene materials: Syntheses, properties and applications. Chem. Soc. Rev. 2014, 43, 7067-7098. [CrossRef]

20. Chen, Z.; Hou, L.Q.; Cao, Y.; Tang, Y.S.; Li, Y. Gram-scale production of B, N co-doped graphene-like carbon for high performance supercapacitor electrodes. Appl. Surf. Sci. 2018, 435, 937-944. [CrossRef]

21. Zhou, Y.; Wang, D.L.; Wang, C.L.; Jin, X.X.; Qiu, J.S. Synthesis of boron, nitrogen co-doped porous carbon from asphaltene for high-performance supercapacitors. Chin. Phys. B 2014, 23, 086101. [CrossRef]

22. Kim, B.H.; Yang, K.S.; Woo, H.G. Boron-nitrogen functional groups on porous nanocarbon fibers for electrochemical supercapacitors. Mater. Lett. 2013, 93, 190-193. [CrossRef]

23. You, B.; Kang, F.; Yin, P.Q.; Zhang, Q. Hydrogel-derived heteroatom-doped porous carbon networks for supercapacitor and electrocatalytic oxygen reduction. Carbon 2016, 103, 9-15. [CrossRef]

24. Lin, Z.; Xiang, X.T.; Peng, S.J.; Jiang, X.C.; Hou, L.X. Facile synthesis of chitosan-based carbon with rich porous structure for supercapacitor with enhanced electrochemical performance. J. Electroanal. Chem. 2018, 823, 563-572. [CrossRef] 
25. Iyyamperumal, E.; Wang, S.Y.; Dai, L.M. Vertically aligned BCN nanotubes with high capacitance. ACS Nano 2012, 6, 5259-5265. [CrossRef] [PubMed]

26. Wang, Q.; Yan, J.; Fan, Z.J. Carbon materials for high volumetric performance supercapacitors: Design, progress, challenges and opportunities. Energy Environ. Sci. 2016, 9, 729-762. [CrossRef]

27. Zhang, Z.J.; Wang, Q.; Zhu, Y.Q.; Chen, X.Y. Nanoporous graphitic carbon materials: Systematic incorporation of $\mathrm{p}-/ \mathrm{m}$-/o-nitroaniline as effective redox additives for largely improving the capacitive performance. Carbon 2016, 100, 564-577. [CrossRef]

28. Wang, Y.H.; Dong, L.Y.; Lai, G.P.; Wei, M.; Jiang, X.B.; Bai, L.Z. Nitrogen-doped hierarchically porous carbons derived from polybenzoxazine for enhanced supercapacitor performance. Nanomaterials 2019, 9, 131. [CrossRef]

29. Pi, Y.T.; Xing, X.Y.; Lu, L.M.; He, Z.B.; Ren, T.Z. Hierarchical porous activated carbon in OER with high efficiency. RSC Adv. 2016, 6, 102422-102427. [CrossRef]

30. Yu, S.; Zhu, X.Q.; Lou, G.B.; Wu, Y.T.; Xu, K.T.; Zhang, Y.; Zhang, L.M.; Zhu, E.H.; Chen, H.; Shen, Z.H.; et al. Sustainable hierarchical porous biomass carbons enriched with pyridinic and pyrrolic nitrogen for asymmetric supercapacitor. Mater. Des. 2018, 149, 184-193. [CrossRef]

31. Wan, L.; Wang, J.L.; Xie, L.J.; Sun, Y.H.; Li, K.X. Nitrogen-enriched hierarchically porous carbons prepared from polybenzoxazine for high-performance supercapacitors. ACS Appl. Mater. Interfaces. 2014, 6, 15583-15596. [CrossRef] [PubMed]

32. Xu, F.; Cai, R.J.; Zeng, Q.C.; Zou, C.; Wu, D.C.; Li, F.; Lu, X.E.; Liang, Y.R.; Fu, R.W. Fast ion transport and high capacitance of polystyrene-based hierarchical porous carbon electrode material for supercapacitors. J. Mater. Chem. 2011, 21, 1970-1976. [CrossRef]

33. Zhu, J.L.; Wei, P.C.; Li, K.K.; He, S.B.; Pan, Z.Y.; Nie, S.X.; Key, J.; Shen, P.K. Self-assembled nanofiber networks of well-separated B and N codoped carbon as Pt supports for highly efficient and stable oxygen reduction electrocatalysis. ACS Sustain. Chem. Eng. 2019, 7, 660-668. [CrossRef]

34. Puthusseri, D.; Aravindan, V.; Madhavi, S.; Ogale, S. 3D micro-porous conducting carbon beehive by single step polymer carbonization for high performance supercapacitors: The magic of in situ porogen formation. Energy Environ. Sci. 2014, 7, 728-735. [CrossRef]

35. Wang, Y.G.; Song, Y.F.; Xia, Y.Y. Electrochemical capacitors: Mechanism, materials, systems, characterization and applications. Chem. Soc. Rev. 2016, 45, 5925-5950. [CrossRef] [PubMed]

36. Farma, R.; Deraman, M.; Talib, I.A.; Omar, R.; Manjunatha, J.G.; Ishak, M.M.; Basri, N.H.; Dolah, B.N.M. Physical and electrochemical properties of supercapacitor electrodes derived from carbon nanotube and biomass carbon. Int. J. Electrochem. Sci. 2013, 8, 257-273.

37. Bello, A.; Barzegar, F.; Momodu, D.; Dangbegnon, J.; Taghizadeh, F.; Fabiane, M.; Manyala, N. Asymmetric supercapacitor based on nanostructured graphene foam/polyvinyl alcohol/formaldehyde and activated carbon electrodes. J. Power Sources 2015, 273, 305-311. [CrossRef]

(C) 2019 by the authors. Licensee MDPI, Basel, Switzerland. This article is an open access article distributed under the terms and conditions of the Creative Commons Attribution (CC BY) license (http://creativecommons.org/licenses/by/4.0/). 